\title{
DEVELOPMENT OF FERTILIZED TUBAL RABBIT EGGS IN DIFFUSION CHAMBERS IN VIVO
}

\author{
M. AHLGREN \\ Department of Obstetrics and Gynaecology, \\ University Hospital, Lund, Sweden \\ (Received 28th Fuly 1965, revised 27th Fanuary 1966)
}

\begin{abstract}
Summary. Fertilized tubal rabbit eggs were transferred to millipore filter chambers (MFC). In one series the eggs were transferred at the two- or four-cell stage to a MFC which was first placed intra-abdominally and $48 \mathrm{hr}$ later moved to the uterus of the same animal. After 24 to 48 $\mathrm{hr}$ under these conditions egg development was significantly retarded compared with the controls. In a second series, fertilized eggs recovered from the Fallopian tube at 65 to $70 \mathrm{hr}$ were transferred to a MFC which was placed within the uterus of the same animal for 2 days. These eggs developed into expanding blastocysts, though smaller than the controls. The results suggest the existence of a tubal factor necessary for eggs to develop into expanding blastocysts.
\end{abstract}

\section{INTRODUCTION}

In an earlier paper (Ahlgren \& Bengtsson, 1962) a new and reliable technique for transplantation of tubal rabbit eggs to the anterior chamber of the eye was described. The method was intended to facilitate the study of egg development before nidation, especially the direct effect of hormones and antifertility compounds. Examination of tubal and intra-ocular eggs showed that they underwent similar development up to the morula stage, but as blastocysts the intra-ocular transplants showed retardation of growth and sometimes degenerative changes.

Cultivation of fertilized rabbit eggs in vitro has been successful from the onecell stage to the early blastocyst stage; however, blastocyst expansion fails, with subsequent collapse and disorganization (Austin, 1961). In searching for a better method for egg cultivation in vitro the report of Algire, Weaver \& Prehn (1954) on diffusion chamber techniques for the culture of cells in vivo suggested the present experiments. Sturgis \& Costellanos (1958) used a similar technique for cultivation of ovarian fragments transplanted to patients without ovaries. In this paper the results of cultivation of fertilized tubal rabbit eggs in intraabdominal and intra-uterine diffusion chambers are reported.

\section{MATERIALS AND METHODS}

Sixteen rabbits of mixed breeds were inseminated, injected with chorionic gonadotrophin, and tubal eggs were recovered as described by Ahlgren \& 
Bengtsson (1962). The eggs were transferred with a pipette to sterile Mrcs (type: nylon reinforced tubes $\mathrm{HA} 3 \mathrm{~mm} \times 2 \mathrm{~cm} \mathrm{lg}$, pore size $0.45 \mu$ ) which had previously been closed at the lower end with MF cement (type MF to MF) and placed in a small clamp in a Petri dish. The dish contained Ringer's solution with about $20 \%$ rabbit serum, leaving the top $5 \mathrm{~mm}$ of the MFC above the surface of the fluid. After transfer of the eggs, the upper end of the MFC was closed by means of another clamp in such a way that some MF cement could be applied above the clamp. In this way contact between the cement and the eggs was prevented. This was assumed to be important, as the cement solvent was a mixture of ethyl alcohol and acetone. After a few minutes, when the cement was dry, all clamps were removed and the MF tube was then ready for deposition in the rabbit.

Two series of experiments were performed. In the first series, containing six rabbits, the eggs were recovered $24 \mathrm{hr}$ after $\mathrm{LH}$ injection and transferred to a MFG which was placed in the abdominal cavity close to the mesosalpinx. Forty-eight hours later a second laparotomy was performed and the MFG was moved to the uterine cavity. The MFC was introduced at the ligated ovarian end of the uterine horn through a small incision which was then sutured. A stop suture was placed at the cervical end of the uterine horn to prevent expulsion of the MFc. In all rabbits the eggs of the contralateral tube and horn served as controls. The eggs from both sides were recovered at 4 to 5 days by flushing the opened MFC and the uterine horn with saline. If the expected number of eggs was not recovered from the MFC, it was cut open longitudinally and placed in a watch-glass with Trichomonas Diluent, a dye used for diagnosis of Trichomonas vaginalis. This dye was found to stain the eggs a much darker red than the MF membrane so that they could easily be detected. In unstained preparations the eggs were difficult to detect against the white background of the MF membrane. This staining procedure did not appear to interfere with the subsequent orcein staining.

In the second series, containing ten rabbits, tubal eggs were recovered unilaterally at 65 to $70 \mathrm{hr}$ and transferred, as described above, to a MFC which was placed in the uterine horn of the same side. At the same time eggs from the other Fallopian tube were recovered and transferred to the corresponding uterine horn, using a fine pipette which was inserted through the uterine wall after ligation of the ovarian end of the horn. At $120 \mathrm{hr}$ eggs were recovered from both sides.

All recovered eggs were measured under the microscope, transferred to a slide, mounted in toto, fixed, and stained with orcein according to the procedure of Chang (1955). The number of mitoses of each egg was counted as accurately as possible.

\section{RESULTS}

First series

Twenty-three eggs were recovered 4 to 5 days after LH injection from MFCs which had spent the 'tubal phase' intraperitoneally before insertion into the uterus. The mean diameter of the eggs was $165 \mu(116$ to $193 \mu)$ and there were 0 to 3 mitoses/egg. The development of the eggs was retarded at the morula 
or early blastocyst stage. Thirteen control blastocysts had a mean diameter of $516 \mu(212$ to $961 \mu)$ with 4 to 14 mitoses each. A further ten control eggs had not grown and were therefore excluded. Among the MFC eggs some might have become retarded spontaneously, but it was not possible to distinguish these from the other eggs in poor condition.

\section{Second series}

Details of thirty-eight MFC eggs and twenty-six controls recovered at $120 \mathrm{hr}$ are given in Table 1. The mean diameter of those eggs which developed into expanding blastocysts was smaller for the MFC eggs than for their control uterine eggs, the difference being statistically highly significant $(P<0 \cdot 001)$. In this series, all eggs were at the late morula or early blastocyst stage at the time of transfer to the MFC or uterus. Eggs which did not grow after transfer were classified as retarded. The mean diameter of the retarded MFC eggs was $162 \mu$ (154 to $193 \mu$ ) and that of the retarded control eggs $158 \mu(116$ to $193 \mu)$. These eggs were thus equally retarded.

The number of mitoses proved difficult to count with accuracy by the method described, and was not statistically analysed.

\section{TABLE 1}

DEVELOPMENT, DIAMETER AND NUMBER OF MITOSES OF RABBIT EGGS RECOVERED AT $120 \mathrm{hr}$

\begin{tabular}{|c|c|c|c|c|c|c|}
\hline \multirow{2}{*}{$\begin{array}{l}\text { Recovered } \\
\text { from }\end{array}$} & \multicolumn{2}{|c|}{ No. of eggs } & \multicolumn{4}{|c|}{ Expanding blastocysts } \\
\hline & Total & Retarded & No. & $\begin{array}{c}\text { Mean diameter } \\
\mu \pm S . E .\end{array}$ & $\begin{array}{c}\text { Range } \\
(\mu)\end{array}$ & $\begin{array}{l}\text { Mean No. of } \\
\text { mitoses }\end{array}$ \\
\hline $\begin{array}{l}\text { MFC } \\
\text { Uterus }\end{array}$ & $\begin{array}{l}38 \\
26\end{array}$ & $\begin{array}{l}15 \\
10\end{array}$ & $\begin{array}{l}23 \\
16\end{array}$ & $\begin{array}{r}620 \pm 46 \\
1078 \pm 72\end{array}$ & $\begin{array}{l}290-1252 \\
560-1565\end{array}$ & $\begin{array}{r}5(0-15) \\
20(8-35)\end{array}$ \\
\hline
\end{tabular}

MFC, millipore filter chamber. S.E., standard error of the mean.

\section{DISCUSSION}

From the first series of experiments it may be concluded that eggs which had spent both the tubal phase and the intra-uterine phase in the MFCs grew very little compared with the control eggs. The second series of experiments was performed in order to study whether the MFC itself had a growth depressing effect. The eggs were allowed to develop under physiological conditions during the tubal phase. With the technique described, both experimental and control eggs were submitted to the same transplantation trauma, the only variable being the MFG. Most of the MFC eggs of the second series developed into expanding blastocysts although they did not develop as far as the controls. The mechanism responsible for this retardation is not known. The impaired contact between the MFC eggs and the endometrium might be of importance as well as a possible toxic effect of the filter membrane. This membrane is known to permit passage of essential metabolites but not of cells (Algire et al., 1954). 
The finding that eggs, which had spent the tubal phase in the Fallopian tube, grew much better in the intra-uterine MFC than eggs which had spent the tubal phase in an intra-abdominal MFC suggests the existence of a tubal factor necessary for normal growth of the egg. Such an explanation could also account for the results of the intra-ocular transplantation experiments. Another explanation could be the possible adverse effect of the longer time which the eggs of the first series spent in the MFC.

\section{AGKNOWLEDGMENTS}

This investigation was supported by grants from the Population Council, New York, U.S.A., and the Medical Faculty, Lund, Sweden. 'Trichomonas Diluent' was supplied by the Swedish Agency of Ortho Pharmaceutical Ltd, Johnson \& Johnson AB. For valuable aid with the statistical analysis, thanks are due to Mr Mats Lörstad.

\section{REFERENCES}

Ahlgren, M. \& Bengtsson, L. Ph. (1962) Transplantation of fertilized rabbit eggs to the anterior chamber of the eye. 7. Reprod. Fert. 3, 89.

Algire, G. H., Weaver, J. M. \& Prehn, R. T. (1954-55) Growth of cells in vivo in diffusion chambers. I. Survival of homografts in immunized mice. F. natn. Cancer Inst. 15, 493.

Austin, G. R. (1961) The mammalian egg. Blackwell Scientific Publications, Oxford.

Chang, M. C. (1955) The maturation of rabbit oocytes in culture and their maturation, activation, fertilization and subsequent development in the Fallopian tubes. F. exp. Zool. 128, 379.

Sturgis, S. H. \& Gastellanos, H. (1958) Ovarian homografts in the primate: experiences with millipore filter chambers. Am. F. Obst. Gynec. 76, 1132. 